\title{
Parametric Study of the Seismic Response of Base Isolated Liquid Storage Tanks with Lead-Core Elastomeric Bearings
}

\author{
G. YAZICI \\ Department of Civil Engineering, Istanbul Kültür University, Ataköy Campus, 34156, Bakırköy, Istanbul, Turkey
}

\begin{abstract}
Field reports from past earthquakes indicate that liquid storage tanks are quite susceptible to earthquake related damages due to the sloshing motion of the contained liquid and that the failure of these structures can have catastrophic impacts on the environment in addition to significant financial losses. Recently, the use of seismic response modification strategies such as base isolation and energy dissipation systems have been extended to liquid storage tanks, particularly large liquified natural gas tanks, in order to protect them from the damaging effects of earthquakes. Base isolation involves the installation of horizontally flexible base isolation bearings under the liquid storage tanks to extend the vibration period of the structure and to provide an additional mechanism for energy dissipation. This paper investigates the effects of the variation of mechanical properties of lead-core elastomeric base isolation bearings on the dynamic response of liquid storage tanks through a comprehensive parametric study which was conducted with a script that uses the Matlab state-space solvers. The paper begins by outlining the mechanical analogue system to be used for calculating the overturning moment and the base shear in tank wall as well as the free surface displacements for a cylindrical liquid storage tank subjected to horizontal base excitation. The nonlinear force-displacement characteristics of the bearings are modelled with the Bouc-Wen hysteresis model. Results of the parametric study show that base isolation can be effective at decreasing the base shear and that special attention must be paid to the increases in the sloshing displacements in determining the freeboard height.
\end{abstract}

DOI: 10.12693/APhysPolA.125.382

PACS: 91.30.Px, 05.45.-a, 47.11.-j

\section{Introduction}

Aboveground cylindrical liquid storage tanks are widely used to store water, fuel, and industrial chemicals. Field reconnaissance reports suggest that these structures perform poorly during earthquakes and the failure of these critical infrastructural system components can result in significant damages to the environment in addition to financial losses [1-5].

Recently, implementations of seismic isolation and energy dissipation systems have been extended to liquid storage tanks, especially large capacity liquefied natural gas (LNG) storage tanks, in order to improve their performance during earthquakes. Seismic isolation works by installing horizontally flexible bearings under a structure which serves to extend its vibration period beyond the predominant vibration period of the ground motion and by increasing its energy dissipation capability. A combination of elastomeric seismic isolation bearings and lead-core elastomeric seismic isolation bearings is a widely used approach for the seismic isolation of liquid storage tanks [6].

A serious issue with the use of seismic isolation bearings is that a slight change in their mechanical properties due to various factors such as aging, changes in temperature and contamination can have a strong impact on the seismic response of the supported structure. Therefore, it is vital to investigate the implications of the likely changes in mechanical properties of seismic isolation bearings in the estimation of design forces of liquid storage tanks.

This paper investigates the effects of the variation of mechanical properties of lead-core elastomeric base isola- tion bearings on the dynamic response of liquid storage tanks through a comprehensive parametric study which was conducted with a script that uses the Matlab state-space solvers.

\section{Lead-core elastomeric seismic isolation bearings}

Elastomeric seismic isolation bearings are composed of alternating layers of rubber and steel shims. The total thickness of the rubber layers is used to adjust the horizontal stiffness of the bearing whereas the steel shims are used to provide vertical rigidity to the bearings. A cylindrical lead-core may be inserted into elastomeric bearings to increase energy dissipation [7].

A lead-core elastomeric isolator can be modeled as bilinear spring with an elastic horizontal stiffness of $k_{\mathrm{e}}$ and a post-yielding stiffness of $k_{\mathrm{p}}$. Equation (1) can be used to calculate the restoring force on a lead-core elastomeric isolation bearing where $D_{y}$ represents the yield displacement; $\alpha_{\mathrm{LRB}}$ represents the ratio of the horizontal post-yield stiffness to the elastic stiffness and $v_{\mathrm{b}}$ represents the horizontal displacement of the bearing. The nondimensional parameter $Z$ which controls the transition between the elastic stiffness and the post-yield stiffness can be obtained by using the Bouc-Wen plasticity model $[8,9]$ given in Eq. (2), where $\beta, \gamma, A$, and $\eta$ are dimensionless variables used for describing the shape of the hysteresis loop of the bearing shown in Fig. 1. The values of $\beta=0.50, \gamma=0.50, A=1$ and $\eta=1$ have been selected to describe the shape of the hysteresis loop of the lead-core elastomeric isolation bearings in this study [10]:

$$
\begin{aligned}
& F_{\mathrm{lrb}}=\alpha_{\mathrm{lrb}} k_{\mathrm{e}} v_{\mathrm{b}}+\left(1-\alpha_{\mathrm{lrb}}\right) k_{\mathrm{e}} D_{y} Z, \\
& D_{y} \dot{Z}+\gamma\left|\dot{v}_{\mathrm{b}}\right| Z|Z|^{\eta-1}+\beta \dot{v}_{\mathrm{b}}|Z|^{\eta}-A \dot{v}_{\mathrm{b}}=0 .
\end{aligned}
$$




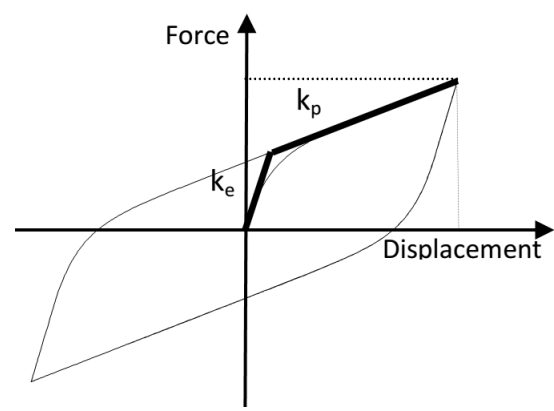

Fig. 1. Hysteresis loop of a lead-core elastomeric isolation bearing.

\section{Mechanical model of the isolated liquid storage tank}

The mechanical analogue system for liquid storage tanks with rigid walls proposed by Veletsos (1984) was used to estimate the hydrodynamic response of the contained liquid. Continuous mass of the contained liquid is represented with a series of discrete single degree of freedom systems, mechanical properties of which can be obtained using analytical expressions [11]. Figure 2 shows the mechanical model of the seismically isolated liquid storage tank resting on lead-core elastomeric isolation bearings. Impulsive component of the contained liquid which moves in unison with the tank is represented with mass $m_{0}$ connected rigidly to the tank wall. Convective component of the contained liquid which is associated with sloshing is represented with masses $m_{1}$ to $m_{5}$ connected to the tank wall with springs of stiffness $k_{1}$ to $k_{5}$. Mass of the base $m_{\mathrm{b}}$ includes the impulsive mass $m_{0}$ and the mass of the base plate $m_{\mathrm{t}}$. Impulsive and convective masses are assumed to be attached to the wall at heights $h_{0}$ to $h_{5}[6]$.

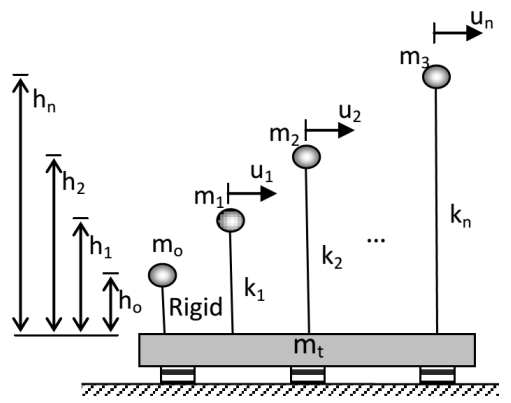

Fig. 2. The mechanical model of the seismically isolated liquid storage tank.

Equations of motion of the seismically isolated tank in terms of relative displacements are presented in Eqs. (3) to (8) where Eqs. (3) through (7) describe the motion of the convective modes

$$
\begin{aligned}
& m_{1} \ddot{u}_{1}+k_{1}\left(u_{1}-u_{\mathrm{b}}\right)=0, \\
& m_{2} \ddot{u}_{2}+k_{2}\left(u_{2}-u_{\mathrm{b}}\right)=0, \\
& m_{3} \ddot{u}_{3}+k_{3}\left(u_{3}-u_{\mathrm{b}}\right)=0, \\
& m_{4} \ddot{u}_{4}+k_{4}\left(u_{4}-u_{\mathrm{b}}\right)=0, \\
& m_{5} \ddot{u}_{5}+k_{5}\left(u_{5}-u_{\mathrm{b}}\right)=0, \\
& m_{\mathrm{b}} \ddot{u}_{\mathrm{b}}+\sum_{j=1}^{5} m_{j} \ddot{u}_{j}+F_{\text {lrb }}=0 .
\end{aligned}
$$

Variation of the base shear, overturning moment acting on the tank wall and overturning moment acting on the tank foundation are calculated by Eqs. (9), (10), and (11) where $A_{j}(t)$ represents the acceleration response of the $j$-th convective oscillator. Heights of the impulsive and convective masses to be used in the calculation of the overturning moment acting on the foundation are denoted by $h_{0}^{\prime}$ and $h_{i}^{\prime}$, respectively $[6,11]$ :

$$
\begin{aligned}
& Q(t)=m_{0} \ddot{v}_{\mathrm{b}}(t)+\sum_{j=1}^{\infty} m_{j} A_{j}(t), \\
& M(t)=m_{0} h_{0} \ddot{v}_{\mathrm{b}}(t)+\sum_{j=1}^{\infty} m_{j} h_{j} A_{j}(t), \\
& M^{\prime}(t)=m_{0} h_{0}^{\prime} \ddot{v}_{\mathrm{b}}(t)+\sum_{j=1}^{\infty} m_{j} h_{j}^{\prime} A_{j}(t) .
\end{aligned}
$$

Sloshing displacement at the tank wall in the direction of the ground motion is calculated with Eq. (12) where $\lambda_{j}$ represents the $j$-th root of $J_{1}^{\prime}(\lambda)=0$ and $g$ represents the gravitational acceleration. Peak values of the base shear, overturning moment and liquid surface displacements are calculated using the SRSS method [11]:

$$
d_{\mathrm{w}}(t)=R\left[\sum_{j=1}^{\infty} \frac{2}{\lambda_{j}^{2}-1} \frac{A_{j}(t)}{g}\right] \text {. }
$$

\section{Parametric study}

A parametric analysis has been conducted with a Matlab script developed by the author, which calculates the maximum base shear, overturning moments, sloshing displacements, as well as the isolator displacements and creates normalized plots which facilitate the evaluation of the effects of the changes in the mechanical properties of the isolator bearings on the seismic response of the tank.

The cylindrical aboveground liquid storage tank used in the parametric analysis has a radius of $42 \mathrm{~m}$ and a liquid height of $36 \mathrm{~m}$ and is supported by lead core elastomeric seismic isolators with a target seismic isolation period of $3 \mathrm{~s}$ calculated from the post yield stiffness of the bearings. East-West component of the 1992 Erzincan (Turkey) earthquake has been used as the horizontal earthquake acceleration time-history record for this study.

The effect of the variation of the ratio of the post-yield stiffness to elastic stiffness and the normalized yield 
strength $\left(F_{y} / W\right)$ on the peak horizontal isolation system displacements are presented in Fig. 3.

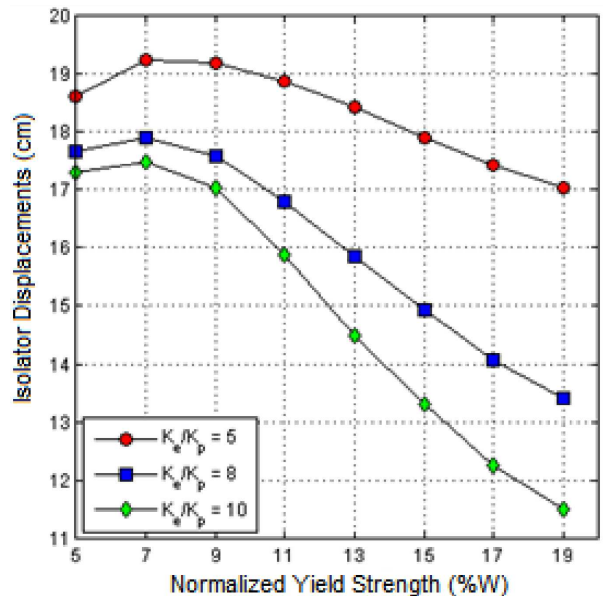

Fig. 3. Effects of the variation of normalized yield force and $k_{\mathrm{e}} / k_{\mathrm{p}}$ ratio on isolator displacements.

Effects of the variation of the ratio of the post-yield stiffness to elastic stiffness and the normalized yield strength $\left(F_{y} / W\right)$ on the hydrodynamic forces and overturning moments exerted on the tanks as well as the sloshing displacements are presented in Fig. 4.

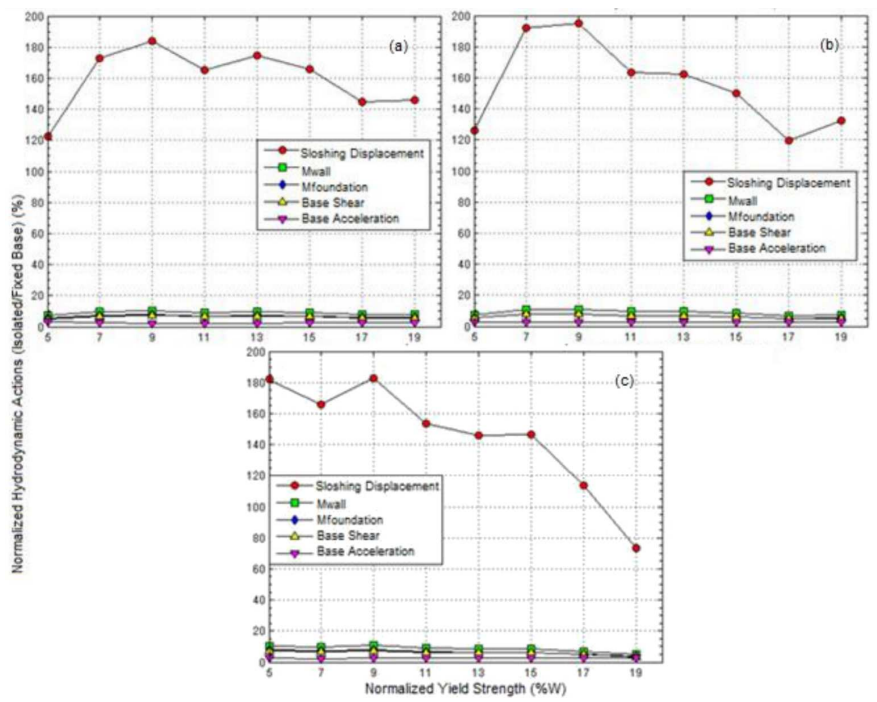

Fig. 4. Effects of the variation of normalized yield strength and $k_{\mathrm{e}} / k_{\mathrm{p}}$ on the tank design parameters (a) $k_{\mathrm{e}} / k_{\mathrm{p}}=6$, (b) $k_{\mathrm{e}} / k_{\mathrm{p}}=8$, (c) $k_{\mathrm{e}} / k_{\mathrm{p}}=6$.

An evaluation of Figs. 3 and 4 shows that lead-core elastomeric isolators were quite effective at reducing the hydrodynamic base shear and overturning moments acting on the tank wall and tank foundation as these values are less than the $20 \%$ of the corresponding values for the fixed based tank. Sloshing displacements, on the other hand, have increased up to $200 \%$ of the corresponding value for the fixed based tank. Therefore, there is a need to increase the freeboard height of isolated liquid storage tanks in order to avoid spilling of contents or damages to the roof. Increasing the normalized yield strength beyond $9 \%$ of the tank weight generally helped to reduce the hydrodynamic base shear and overturning moments in the liquid storage tank as well as the bearing displacements. Variation of the ratio of the elastic stiffness to the post-yield stiffness did not have significant effect on changing the hydrodynamic forces and overturning moments but had a more pronounced effect on reducing the bearing displacements.

\section{Results and conclusions}

Lead-core elastomeric isolation bearings can be quite effective in reducing the hydrodynamic loads acting on the tank due to the sloshing action of the contained liquid during earthquakes. However, it should also be noted that there is a need to increase the freeboard heights of seismically isolated tanks in order to accommodate increased sloshing displacements.

Parametric analysis of the isolated tank within the limits of potential variations of components' mechanical properties and evaluation of the fluctuations in the levels of change in hydrodynamic loads with respect to the values obtained for the ground supported tank through normalized graphics as prescribed in this study significantly facilitates the design of the seismic isolation system and the estimation of the hydrodynamic loads used in tank design.

\section{References}

[1] H. Sezen, A.S. Whittaker, J. Perform. Constr. Fac. 20, 28 (2006).

[2] E. Krausmann, A.M. Cruz, B. Affeltranger, J. Loss Prevent. Proc. 23, 242 (2010).

[3] C. Scawthorn, G.S. Johnson, Eng. Struct. 22, 727 (2000).

[4] G.C. Manos, R.W. Clough, Earthq. Eng. Struct. D 13, 449 (1985).

[5] R. Nielsen, A.S. Kiremidjian, J. Struct. Eng.-ASCE 112, 1481 (1986).

[6] G. Yazici, Ph.D. Thesis, Istanbul Technical University, 2008 (in Turkish).

[7] J.M. Kelly, F. Naeim, in: Design of Seismic Isolated Structures From Theory to Practice, Wiley, New York 1999, p. 49.

[8] Y.K. Wen, J. Eng. Mech-ASCE 102, 249 (1976).

[9] Y.J. Park, Y.K. Wen, A.H. Ang, Earthq. Eng. Struct. D 14, 543 (1986).

[10] N. Makris, S. Chang, "Effect of Damping Mechanisms on the Response of Seismically Isolated Structures", PEER Report 1998/6, University of California, Berkeley 1998.

[11] A.S. Veletsos, in: Proc. Technical Council on Lifeline Earthquake Engineering Guidelines for the Seismic Design of Oil and Gas Pipeline Systems, ASCE, New York 1984, p. 255 and p. 443. 